\title{
Formação do plexo braquial e sistematização dos territórios nervosos em membros torácicos de lobos- marinhos Arctocephalus australis
}

\author{
Brachial plexus formation and the nervous territories on thoracic limb of \\ Arctocephalus australis
}

\author{
Daniel Alexandre Stüpp de SOUZA ${ }^{1}$; Tiane Ferreira de CASTRO ${ }^{2}$; Raphaela da Cunha FRANCESCHI ${ }^{4}$; \\ Rodolfo Pinho SILVA FILHO ${ }^{3}$; Malcon Andrei Martinez PEREIRA ${ }^{4}$ \\ ${ }^{1}$ Programa de Pós-Graduação em Biologia Animal e Laboratório de Ornitologia e Mastozoologia, Departamento de Zoologia, \\ Instituto de Biociências Universidade Federal do Rio Grande do Sul, Porto Alegre-RS \\ ${ }^{2}$ Médica Veterinária \\ ${ }^{3}$ Centro de Reabilitação de Animais Marinhos da Fundação Universidade Federal de Rio Grande do Sul, Porto Alegre-RS \\ ${ }^{4}$ Programa de Pós-Graduação em Neurociências e Laboratório Neurobiologia Comparada do Departamento Fisiologia do \\ Instituto Ciências Básicas Saúde da Universidade Federal Rio Grande do Sul, Porto Alegre-RS
}

\begin{abstract}
Resumo
Para a realização do estudo acerca do plexo braquial (PB) e dos territórios nervosos do membro torácico de lobosmarinhos (Arctocephalus australis) foram utilizados dois animais. A pele foi retirada e procedeu-se a identificação da musculatura do membro torácico e região peitoral. Em seguida foram aplicadas compressas de solução de ácido acético glacial 3\% na musculatura, com o intuito de facilitar a dissecação realizada macroscopicamente. Nos espécimes analisados notou-se a emergência do plexo braquial a partir do sexto nervo cervical até o primeiro nervo torácico. Destas quatro raízes se formam os troncos de nervos de mesmo número, cujos ramos ventrais constituirão seu arranjo e distribuição territorial. Destes quatro troncos surgem os 12 nervos componentes do PB, sendo encontrados nervos que se formam a partir de apenas um segmento (supra-escapular, peitoral cranial, torácico lateral, toracodorsal e torácico longo) e também nervos que surgem a partir de mais de um segmento, sendo assim denominados plurissegmentares (subescapular, músculo-cutâneo, axilar, mediano, peitoral caudal, ulnar e radial). Nesse sentido, foi observada uma constância na inervação da musculatura, articulações e ossos do membro torácico, de onde podemos assim inferir que existe um padrão claramente definido na delimitação dos territórios nervosos.
\end{abstract}

Palavras-chave: Plexobraquial. Arctocephalus australis. Membro torácico.

\begin{abstract}
For the study concerning the brachial plexus (BP) and the nervous territories of the thoracic limb of South American Fur Seal (Arctocephalus australis), two animals had been used. Their skin was removed and the musculature of the thoracic limb and pectoral region was identified. After that compresses of glacial acetic acid solution of $3 \%$ had been applied in the musculature, in order to facilitate the carried through dissection. In analyzed specimens it was observed the emergency of BP from the sixth cervical nerve until the first thoracic nerve. From these four roots trunks of nerves of the same number are formed, whose ventral branches will constitute its arrangement and territorial distribution. From these four trunks emerge the 12 component nerves of the BP, some of them come from only one segment (supra scapular, cranial pectoral, lateral thoracic, thoraco-dorsal and long thoracic), while others come from more than a segment (sub scapular, muscle-cutaneous, axillary, median, caudal pectoral, ulnar and radial). In this direction,this observed constancy in the innervation of the musculature, joints and bones of the thoracic limb, led us to infer that a definite pattern in the delimitation of the nervous territories clearly exists.
\end{abstract}

Keywords: Brachial plexus. Arctocephalus australis. Thoracic limb.

\section{Introdução}

O lobo-marinho (Mammalia, Carnivora, Otariidae) por conta de sua pele e óleo valiosos, já foi um animal caçado em larga escala ${ }^{1}$, no entanto, nos dias atuais é protegido em todos os países em que se encontra ambientado, mas ainda assim encontra-se um número
Correspondência para:

Malcon Andrei Martinez Pereira

Laboratório Neurobiologia Comparada, Departamento Fisiologia,

ICBS - UFRGS, Rua Sarmento Leite, 500

Porto Alegre, RS, Brazil, Zip code: $90046-900$

Telephone: (51) 33083305, Fax: (51) 33083092

e-mail: malconantato@yahoo.com.br

Recebido para publicação: 22/11/2005

Aprovado para publicação: 20/09/2007 
reduzido de espécimes em relação àquele existente anteriormente. Exemplares desta espécie são comumente encontrados no oceano Atlântico, desde a costa do Rio Grande do Sul até o Cabo Horn, e deste até o litoral do Peru, no oceano Pacífico ${ }^{2}$. Frequentemente são relatados derramamentos de óleo que provocam a morte destes animais, assim como existem relatos de assassinatos por pescadores que alegam serem prejudicados por lobos-marinhos, pois estes seriam competidores vorazes em busca dos peixes mais valiosos, além de destruírem redes de pesca ${ }^{1}$.

Os machos desta espécie atingem em média dois metros de comprimento e pesam de 150 a 200 quilos; já as fêmeas medem 1,5 metro e, em contraste com os machos, podem atingir um peso de 30 a 60 quilos, em média ${ }^{1}$. Seus hábitos alimentares são essencialmente carnívoros e sua dieta é basicamente composta de peixes, crustáceos e moluscos aquáticos ${ }^{2}$.

Animais como o lobo-marinho frequentemente não têm sua anatomia estudada com rigor. A literatura ocorrente faz referência apenas à miologia e osteologia do membro torácico de leões-marinhos ${ }^{3}$; ou realiza uma análise comparativa entre miologia e osteologia de leão-marinho e foca ${ }^{4}$, ainda assim de maneira superficial. Com base neste fato, pode-se afirmar que dados literários referentes a mamíferos marinhos são escassos e restringem-se, quase que em sua totalidade, a descrições de suas características físicas, reprodução, hábitos e predadores.

Devido às fatalidades que acometem esta espécie e ao desconhecimento de sua anatomia, são necessárias informações adicionais que forneçam subsídios aos profissionais que trabalham em sua reabilitação e no tratamento de suas lesões, para que, desta maneira, atuem mais eficientemente, visando à preservação desta tão ameaçada espécie.

\section{Material e Método}

Foram utilizados para esta descrição dois lobosmarinhos (Arctocephalus australis), um de cada sexo, oriundos do Centro de Reabilitação de Ani- mais Marinhos da Fundação Universidade Federal de Rio Grande (CRAM-FURG). Neste, foi constatado o óbito dos espécimes devido à desidratação, por meio de autópsia onde os órgãos localizados nas regiões torácica e abdominal foram retirados para a realização de estudos naquela instituição. Assim, os animais recebidos encontravam-se eviscerados, mas com a integridade do plexo braquial (PB) preservada. Para a identificação da origem do PB e delimitação dos territórios nervosos dos espécimes, o primeiro passo consistiu na retirada da pele responsável pelo revestimento do tórax e membro torácico, procedendo-se incisões nas extremidades cranial, caudal e distal, deste. Em sequência, foram aplicadas compressas de solução de ácido acético glacial 3\%5, com o objetivo de provocar a dilatação das bainhas que envolvem o tecido nervoso, propiciando assim uma melhor visualização dos nervos componentes do plexo braquial e de seus ramos, responsáveis pela motricidade do membro torácico. Decorridos os 15 minutos necessários para a atuação da solução, os animais foram lavados em água corrente, preservando assim as estruturas nervosas. A seguir partiuse então para a identificação da musculatura, tanto do membro como das regiões cervical e peitoral, e dos nervos por meio de dissecação pela face ventral, sendo esta realizada macroscopicamente devido ao calibre assumido pelas estruturas nervosas após a realização do método supracitado. Tendo sido decorridos os passos citados, foram produzidos esquemas gráficos e fotográficos, objetivando documentar visualmente os resultados encontrados.

\section{Resultados e Discussão}

O plexo braquial (PB) do lobo-marinho é formado pelos ramos ventrais do sexto, sétimo e oitavo nervos cervicais e primeiro nervo torácico, sendo esta descrição compatível à existente para cão ${ }^{6,7,8}$ e gato ${ }^{9,10}$; no entanto, a constituição do PB observada em lobo-marinho não teve variação quanto à presença de 
ramos contribuintes oriundos do segundo nervo torácico, como pode ocorrer nesses animais.

A emergência do $\mathrm{PB}$ ocorre a partir dos segmentos medulares já anteriormente citados formando troncos nervosos de mesmo número. Os dois primeiros troncos deixam o canal vertebral cranialmente às vértebras correspondentes; já o terceiro tronco nervoso tem sua origem a partir do espaço entre a sétima vértebra cervical e a primeira torácica, e caudalmente a esta ocorre a formação do quarto tronco, que tem o início de seu trajeto a partir do espaço entre a primeira e a segunda vértebra torácica.

Após a saída do canal vertebral, os quatro troncos nervosos componentes do $\mathrm{PB}$ posicionam-se entre o músculo intertransverso, de onde partem em direção ao membro torácico. Uma peculiaridade a ser notada ocorre em relação ao quarto tronco nervoso: este ao emergir da medula espinhal encontra-se entre a primeira e a segunda costela. No entanto, para assumir o mesmo posicionamento dos outros troncos formadores do PB, cruza o bordo cranial da primeira costela, de modo imediatamente proximal à articulação costo-vertebral.

Destes quatro troncos nervosos surgirão doze nervos responsáveis pela inervação de músculos, ossos, articulações e pele do membro torácico, semelhantemente ao que ocorre no homem ${ }^{11}$. Neste sentido podemos relatar que destes nervos, apenas três são unissegmentares ${ }^{11}$ : peitoral cranial, subescapular e toracodorsal (Figuras 1-2). Os outros nove nervos apresentam-se compostos de mais de uma raiz, sendo então denominados plurissegmentares ${ }^{11}$ (Figura 1).

Os nervos peitorais de lobo-marinho, assim como em cães e gatos, representam um grupo que



Figura 1 - Fotografia evidenciando a emergência dos troncos nervosos oriundos dos segmentos medulares $\mathrm{C}_{6}, \mathrm{C}_{7}, \mathrm{C}_{8}$ e $\mathrm{T}_{1}$ que originam os nervos do Plexo Braquial em Arctocephalus australis. Os asteriscos marcam a emissão de feixes nervosos de um segmento para outro, configurando a formação dos nervos plurissegmentares. Seta indicando o eixo crânio-dorsal 




Figura 2 - Fotografia mostrando a disposição e o trajeto dos nervos provenientes dos segmentos medulares $\mathrm{C}_{6}-\mathrm{T}_{1}$, que constituem o Plexo Braquial em Arctocephalus australis, discriminação no sentido anti-horário: supraescapular (SE), peitoral cranial (PC), subescapular (Sb), toracodorsal (TD), axilar (A), radial (R), músculo-cutâneo $(\mathrm{Mc})$, mediano $(\mathrm{M})$, ulnar (U), torácico lateral $(\mathrm{Tl})$, torácico longo $(\mathrm{TL})$ e peitoral caudal $(\mathrm{Pc})$. Seta indicando o eixo crânio-dorsal

pode ser dividido em nervo peitoral cranial e nervo peitoral caudal (Figura 2) ${ }^{10,12}$, tendo, no entanto origens opostas. O nervo peitoral cranial origina-se a partir do sexto nervo cervical, e o nervo peitoral caudal tem sua emergência do oitavo nervo cervical e do primeiro nervo torácico (Figura 2). Essas origens são discrepantes em relação às encontradas em cão e gato, onde nos primeiros animais todos os quatro principais segmentos que originam o $\mathrm{PB}$ têm participação na formação dos nervos peitorais $^{6,7,8}$, de maneira semelhante ao que ocorre em gatos, a não ser pela ausência do sexto nervo cervical $^{9,10}$. Assim os nervos peitorais são responsáveis pela motilidade dos músculos peitoral superficial e peitoral profundo.
A origem do nervo supra-escapular (Figura 2) ocorre a partir da união entre os ramos ventrais do sexto e o sétimo nervos cervicais, indo de encontro à descrição da emergência deste nervo em cães $^{6,7,8}$, mas diferindo do existente relato no caso do gato ${ }^{9,10}$, em que a origem do nervo supraescapular ocorre apenas a partir do sexto nervo cervical. A união do sexto e sétimo nervos cervicais se dá por meio de uma alça dupla, em que a contribuição do segundo nervo é bastante delgada em relação ao primeiro. Da porção mais externa desta estrutura é que ocorre a emergência do nervo supraescapular (Figura 2), que tem seu trajeto delimitado pelos músculos subescapular e supraespinhal, sendo acompanhado pelos vasos supraescapulares. Desta maneira, este nervo é responsável 
pelo suprimento motor dos músculos supraespinhal e infraespinhal, e ainda de acordo com Crouch ${ }^{13}$, em gatos o nervo supra-escapular pode enviar ramos para o músculo subescapular.

Do sétimo nervo cervical ocorre a formação do nervo subescapular (Figura 2), o que contrasta com a descrição para cão e gato em que fibras derivadas do sexto nervo cervical também seriam formadoras do nervo subescapular ${ }^{10,12}$. Porém, de acordo com Reimers ${ }^{9}$, quando há apenas um nervo subescapular no cão, assim como acontece em lobo-marinho, a origem deste pode se dar apenas do sétimo nervo cervical. Sendo supridos pelo nervo subescapular, encontramse os músculos subescapular e redondo maior, onde no caso deste segundo músculo o suprimento ocorre por meio de uma delicada ramificação.

O nervo toracodorsal (Figura 2) deriva suas fibras unicamente do sexto nervo cervical, diferindo esta origem da encontrada em cães e gatos. Nos primeiros o nervo toracodorsal é formado a partir do oitavo nervo cervical ${ }^{7,8}$, enquanto no caso de gatos, a formação deste nervo se dá também do sétimo nervo cervi$\mathrm{cal}^{9,10}$. Seguindo junto aos vasos toracodorsais, em sua distribuição periférica, este nervo se distribui para o músculo grande dorsal ${ }^{10}$.

O nervo torácico lateral (Figura 2) tem sua origem dos ramos ventrais do oitavo nervo cervical e do primeiro nervo torácico, concordando com a descrição de Goshal ${ }^{10}$ para gatos, mas diferindo daquela relatada no cão, em que o segundo nervo torácico também é responsável pela formação do nervo torácico lateral, segundo este mesmo autor. Este nervo é o responsável pela motilidade do músculo cutâneo do tronco ${ }^{7,8}$.

Possuindo origem idêntica à encontrada em cão $0^{6,7,8}$, o nervo torácico longo (Figura 2) se forma a partir de ramificações dos sétimo e oitavo nervos cervicais, logo após a passagem destas raízes nervosas pela cúspide da sétima vértebra cervical. Desta maneira, a origem deste nervo difere da encontrada em gatos, em que a formação do nervo torácico longo se dá unicamente a partir do ramo ventral do sétimo nervo cervical ${ }^{10,13}$. Após a união das raízes que o formam, o nervo torácico longo corre superficialmente junto ao músculo serrátil ventral, sendo totalmente consumido por este ${ }^{10}$.

A origem do nervo axilar (Figura 2) se dá igualmente àquela descrita para o cão ${ }^{6,7,8}$, sendo composta pelas raízes nervosas do sétimo e oitavo nervos cervicais, no entanto contrariando a descrição ocorrente para gato, em que a participação do oitavo é trocada com o sexto nervo cervical ${ }^{9,10}$. É também a partir da união das raízes que originam este nervo que se forma a alça axilar, estrutura esta responsável por oferecer suporte e sustentação à artéria de mesmo nome nesta região do membro torácico. $\mathrm{O}$ nervo axilar tem seu trajeto localizado superficialmente aos músculos flexores da articulação do úmero, nos quais a motilidade é possível graças a este nervo ${ }^{8}$. Em relação à flexão da articulação supracitada, os músculos que estão envolvidos nesta atividade são: redondo maior, deltoide e a porção caudal do músculo subescapular. Além destes músculos o nervo axilar também atua na superfície caudal da cápsula da articulação do úmero e ainda, seus ramos cutâneos emergem lateralmente sendo responsáveis pela inervação de fáscia e pele na região antebraquial.

Ao ocorrer a derivação de fibras do oitavo nervo cervical e do primeiro torácico, se dá a formação do nervo ulnar (Figura 2), da mesma maneira como acontece no cão ${ }^{7,8}$, mas em se tratando de gatos, a formação do nervo ulnar conta ainda com a participação do sétimo nervo cervical ${ }^{10}$. Sua emergência localiza-se juntamente à dos nervos mediano e músculo-cutâneo, e em posição oposta ao nervo peitoral caudal. Ao originar-se o nervo ulnar está posicionado superficialmente, mas ao circundar o olécrano passa a acompanhar o trajeto dos músculos flexores digitais, e ao nível da articulação metacarpofalangeana ocorre sua divisão em nervos digitais palmares próprios I e II. Através de seus ramos terminais, é responsável 
pela motilidade dos músculos flexor ulnar do carpo, flexor digital profundo, flexores dos dígitos I e II e interósseo, e ainda atua na sensibilidade cutânea dorsolateral nas regiões de carpo e dígito.

Origem idêntica ao nervo ulnar, igualmente à descrita para cão ${ }^{6,7,8}$ e gato $^{10,13}$, pode ser observada no caso do nervo mediano (Figura 2), pois estes aliados ainda aos nervos peitoral caudal e músculo-cutâneo em sua origem formam um tronco nervoso comum. Estrutura semelhante pode ser constatada em cães, no entanto neste caso os componentes são apenas os nervos mediano e ulnar (Figura 2) ${ }^{10}$. Ao nível da articulação do úmero esta associação se desfaz e o nervo mediano segue em seu trajeto, cranialmente ao olécrano da ulna, passando sobre o músculo pronador redondo, e de maneira semelhante ao nervo ulnar, divide-se em nervos digitais palmares próprios III e IV na região da articulação metacarpofalangeana. Além do músculo pronador redondo, o nervo mediano inerva os flexores dos dígitos III e IV e o flexor radial do carpo. $\mathrm{Na}$ área sensitiva, o território de atuação deste nervo é basicamente a superfície cutânea palmar das regiões de metacarpo e dígitos, por meio de delgados ramos.

Sendo o componente do PB com maior número de raízes, o nervo radial (Figura 2) origina-se dos ramos ventrais do sétimo e do oitavo nervos cervicais e do primeiro nervo torácico, semelhantemente ao que acontece em carnívoros domésticos segundo Barone ${ }^{12}$ e Goshal ${ }^{10}$, mas ainda de acordo com Sharp et al. ${ }^{14}$, em cães a origem do nervo radial (Figura 2) pode contar com a participação do segundo nervo torácico. Próximo à articulação do úmero, seu trajeto está intimamente relacionado à artéria axilar, e também nesta região emerge na musculatura, distalmente ao músculo ancôneo, para transpassá-la e assumir trajeto lateral, onde se ramifica triplamente. Desta maneira, além do músculo supracitado, o nervo radial ainda tem atuação na motilidade dos seguintes músculos: tríceps braquial, braquial, tensor da fáscia antebraquial, extensores oblíquos do carpo, radial do carpo, ulnar do carpo, digital comum, digital lateral, oblíquo longo e os supinadores longo e breve $e^{7}$. Através de seus mais delgados ramos, este nervo ainda atua na sensibilidade cutânea das regiões braquial e antebraquial.

Diferindo da observação realizada por Goshal ${ }^{10} \mathrm{em}$ cão, onde se nota o nervo radial como o maior dos componentes do $\mathrm{PB}$, no caso do lobo-marinho esta denominação é conferida ao nervo mediano, que em seu trajeto possui um comprimento aproximadamente duas vezes maior que o nervo radial.

A origem do nervo músculo-cutâneo (Figura 2) é a mesma dos nervos peitoral caudal, ulnar e mediano, ou seja, ocorre do oitavo nervo cervical e primeiro torácico. De maneira antagônica a estes, que ao menos em parte possuíam origem semelhante em carnívoros domésticos ${ }^{7,8,10}$, no caso do nervo músculo-cutâneo sua origem não compete em nada com aquela encontrada nestes animais, pois em gatos ela se dá a partir do sexto e sétimo nervos cervicais ${ }^{9,10}$, e em cães acontece somente deste último segmento ${ }^{7,8}$, ou pode receber pequena contribuição do sexto ou oitavo nervos cervicais ${ }^{15}$. À altura da articulação do úmero ocorre a divisão do nervo músculo-cutâneo em dois ramos. O ramo proximal atua na motilidade do músculo bíceps braquial, enquanto o ramo distal inerva a parte distal do músculo bíceps braquial e também o músculo braquial ${ }^{10}$; e em trajeto cutâneo, este nervo atua na região antebraquial medial. Pode-se observar ainda uma conexão deste último ramo com o nervo mediano, logo abaixo da divisão em ramos do nervo músculo-cutâneo.

Obviamente esta descrição não pode ser considerada como um modelo anatômico definitivo, em virtude do reduzido número de espécimes utilizados, dada a dificuldade em se obter os animais necessários ao estudo, por conta do grau de ameaça de extinção atribuído a estes. Assim, a realização do trabalho só é possível quando alguma fatalidade recai sobre os animais, levando-os então à morte. No entanto, a partir desse momento pode-se tomar o presente relato como 
referência quando se fizerem necessários subsídios à reabilitação de lobos-marinhos, ou de qualquer outra espécie que anatomicamente se assemelhe a esta.

\section{Conclusões}

Mediante os dados observados em nosso trabalho, pôde-se concluir que: o plexo braquial tem origem dos ramos ventrais dos nervos espinhais do sexto, sétimo e oitavo nervos cervicais e do primeiro nervo torácico; variações quanto à contribuição de outros nervos espinhais na formação do plexo não foram observadas; dos quatro troncos que dão origem ao plexo são formados doze nervos, sendo dentre estes, três unissegmentares e

\section{Referências}

1.ELLIS, R. South american fur sea. 1998. Disponível em: $<$ http://marinebio.org/species.asp? $\mathrm{id}=312>$. Acesso em: 30 ago. 2005

2.SWOLGAARD, C. Arctocephalus australi: South American fur seal. Michigan: University of Michigan, 2002. Disponível em: <http://animaldiversity.ummz.umich.edu/site/accounts/ information/Arctocephalus_australis.html $>$. Acesso em: 3 set. 2005.

3. HILDEBRAND, M. Análise da estrutura dos vertebrados. São Paulo: Atheneu, 1995.

4.HOWELL, A. B. Contribution to the comparative anatomy of the eared and earless seals (Genera Zalophus and Phoca). Proceedings U. S. National Museum, v. 73, n. 2736, 1929. Art. 15.

5.RODRIGUES, H. Técnicas anatômicas. 2. ed. Vitória: Arte Visual, 1998.

6. MILLER, M. E.; CHRISTENSEN, G. C.; EVANS, H. E. Anatomy of the dog. Philadelphia: W. B. Saunders, 1964.

7.DYCE, K. M.; SACK, W.O.; WENSING, C. J. G. Tratado de anatomia veterinária. 2. ed. Rio de Janeiro: GuanabaraKoogan, 1987.

8.KÖNIG, H. E.; LIEBICH, H. J. Anatomia dos animais domésticos. Porto Alegre: Artmed, 2002. 2 v. nove plurissegmentares; o maior dos componentes do plexo braquial em termos de extensão é o nervo mediano; o nervo radial possui o maior número de troncos constituintes, sendo derivadas fibras ventrais do sétimo e oitavo nervos cervicais e do primeiro nervo torácico; a partir dos ramos ventrais do oitavo nervo cervical e do primeiro torácico é formado um tronco comum que dá origem aos nervos: peitoral caudal, ulnar, mediano e músculo-cutâneo; na articulação metacarpofalangeana ocorrem s divisões dos nervos ulnar e mediano, em nervos digitais palmares próprios e a inervação digital se dá por meio dos ramos digitais oriundos do nervo ulnar para os dígitos I e II, e do nervo mediano para os dígitos III e IV.

9.REIMERS, H. Der plexus brachialis der Haussäugetire; eine vergleichend-anatomische Studie. Z Anat., v. 76, p. $653-753,1925$

10. GHOSHAL, N. G. Sistema nervoso do carnívoro. In: GETTY, R. SISSON \& GROSSMAN: anatomia dos animais domésticos. 5. ed. Rio de Janeiro: Guanabara-Koogan, 1975.

11.DI DIO, L. J. A. Tratado de anatomia aplicada. São Paulo: Póluss Editorial, 1999. 3 v.

12. BARONE, R. Anatomia comparata del mammiferi doméstici. Bologna: Edagircole, 1974. 3 v.

13. CROUCH, J. E. Text-atlas of cat anatomy. Philadelphia: Lea \& Febiger, 1969.

14.SHARP, J. W.; BAILEY, C. S.; JOHNSON, R. D.; KITCHELL, R. $\mathrm{L}$. Spinal root origin of the radial nerve and nerves innervating shoulder muscles of the dog. Anatomia, Histologia, Embryologia, v. 20, n. 3, p. 205-214, 1991.

15.BOWNE, J. G. Neuroanatomy of the brachial plexus of the dog. 1969. Thesis (Ph.D). Iowa State University, Ames, 1995.

16.INTERNATIONAL COMMITTE ON VETERINARY GROSS ANATOMICAL NOMENCLATURE. Nomina anatomica veterinaria. 4. ed. Zürich, 1994. (Together with nomina histological, 2. ed. rev., 1992 and nomina embriologica veterinaria). 